Portland State University

PDXScholar

6-12-2019

\title{
Barriers to Community Gardening in Portland, OR
}

Jullian Michael Schrup

Portland State University

Follow this and additional works at: https://pdxscholar.library.pdx.edu/honorstheses

Let us know how access to this document benefits you.

Recommended Citation

Schrup, Jullian Michael, "Barriers to Community Gardening in Portland, OR" (2019). University Honors

Theses. Paper 768.

https://doi.org/10.15760/honors.786

This Thesis is brought to you for free and open access. It has been accepted for inclusion in University Honors Theses by an authorized administrator of PDXScholar. Please contact us if we can make this document more accessible: pdxscholar@pdx.edu. 


\title{
Barriers to Community Gardening in Portland, OR
}

by

\section{Jullian Schrup}

An undergraduate honors thesis submitted in partial fulfillment of the requirements for the degree of

\author{
Bachelor of Arts \\ in \\ University Honors \\ and \\ Sociology
}

Thesis Adviser

Julius McGee

Portland State University 
$\underline{\text { Table of Contents }}$

Table of Contents

$\begin{array}{ll}\text { Abstract } & 3\end{array}$

$\begin{array}{ll}\text { Introduction } & 4\end{array}$

Literature Review $\quad 5$

$\begin{array}{ll}\text { Studied Benefits of Community Gardens } & 5\end{array}$

Studies Critically Analyzing Community Garden Impacts $\quad 7$

Urban Agriculture $\quad 8$

Theory $\quad 9$

Grounded Theory $\quad 9$

Eco-Gentrification $\quad 9$

$\begin{array}{ll}\text { Barriers } & 11\end{array}$

$\begin{array}{ll}\text { Project Design } & 13\end{array}$

Data Collection $\quad 15$

$\begin{array}{ll}\text { Coding and Variable Identification } & 16\end{array}$

$\begin{array}{ll}\text { Results } & 18\end{array}$

$\begin{array}{ll}\text { Structural Barriers } & 19\end{array}$

Social Barriers $\quad 23$

$\begin{array}{ll}\text { Cultural Barriers } & 26\end{array}$

$\begin{array}{ll}\text { Discussion } & \mathbf{3 0}\end{array}$

The Significance of the Sample 31

Barrier Terminology $\quad 32$

Variable Reasoning $\quad 32$

Implications for Gentrification 33

Further Research Into Barriers to Community Gardening 34

$\begin{array}{ll}\text { Limitations } & 35\end{array}$

$\begin{array}{ll}\text { Conclusion } & 36\end{array}$

$\begin{array}{lr}\text { Works Cited } & 38\end{array}$ 


\begin{abstract}
$\underline{\text { Abstract }}$
This paper analyzes structural, social and cultural barriers to community gardening in Portland, Oregon. Both the majority of Portland's demographics and the majority of its community gardeners are white, with much of the minority populations being progressively gentrified and displaced outside of the urban center. Exasperating this displacement is Portland's uneven investment in sustainable and green infrastructure in a process currently being studied as eco-gentrification. In tandem with the eco-gentrification literature, there is growing evidence that urban agriculture and community gardens disproportionately benefit white middle-class individuals through exclusionary spaces that omit minority participation. Portland's community garden participation of black and African immigrant residence is less than $2 \%$. The focus of this paper is to understand Portland's low black and African immigrant garden participation by analyzing barriers to community gardening. To do so, Grounded Theory is employed to analyze the transcripts of 17 semi-structured in-depth interviews collected from black and African immigrant Portland gardeners.
\end{abstract}


$\underline{\text { Introduction }}$

Community gardens in the United States arose as a response by community leaders to the rapid city migration and an economic depression which created a demand for cheap food in the late 19th century. Poor residents were then offered the opportunity to grow food in vacant lots (Irvine et al., 1999; Hanna and Oh, 2000). Post World War I and II the demand for cheap food in cities fell as large-scale agriculture and refrigeration swept across America and subsequently, community gardens became less popular. During the 1960s and 1970s community gardens experienced a resurgence as many immigrants and southern blacks transformed vacant lots into gardens, adding their own cultural dimensions to gardening (Krasny and Saldivar-Tanka, 2003). Over 1,000,000 community gardeners were reported by the mid-1990s (Malakoff 1995, Bicho 1996). Another surge occurred between 2008 and 2016 as the number of Americans participating in community gardens doubled (National Gardening Association). Currently, community gardens are becoming more and popular as over 2,000,000 US household members participate in community gardens with over 5,000,000 households expressing interest (National Gardening Association). This growing interest in community gardening has led to a surge of academic literature into both the benefits of community gardening and the uneven developments that urban agriculture may produce. Few critical studies explore the barriers to community gardening which may be the major factor in preventing the benefits of community gardening from being equitably distributed.

Key Terms - Barrier: a circumstance or obstacle that keeps people or things apart or prevents communication or progress. Community Gardens: are defined loosely as a single piece of land 
gardened collectively by a group of people. Eco-gentrification: can be defined as an environmental planning agenda that leads to the displacement or exclusion of the most economically vulnerable human populations while espousing an environmental ethic. Urban Agriculture: is the practice of cultivating, processing and distributing food in or around urban areas.

\section{$\underline{\text { Literature Review }}$}

This review of the literature is structured in four sections to elucidate the urban community gardening discourse. The first section articulates the widely researched positive effects of community gardening. The second section understands the critiques of urban community gardening development and how, in some communities, they have been documented to unevenly affect the most powerful groups. The third section focuses on modern applicable theory and the foundation of this paper, and the fourth section explores the research gap and the limited research revolving around barriers to community gardening. This literature review both lays the foundation of this paper and explains why I apply the qualitative analysis grounded theory to the gathered interview transcripts.

\section{Studied Benefits of Community Gardens}

There is considerable and growing research into the positive effects of community gardening. In a review and analysis of the research, Draper and Freedman (2010) conducted a thematic analysis of the data. They found that community gardening improved food security, created economic development, reduced crime in an area, improved youth education, development, and employment, increased neighborhood beautification and provided a space for 
cultural preservation and expression. Community gardens were found to enhance positive dietary habits of participant's households, a total increase in Total Emotional Score and greater physical activity among both youth and adults (Austin et al. 2006, Armstrong 2000, Hannah and Oh 2000, Twiss et al. 2003), and land use issues were documented as to mobilize people from diverse backgrounds and varying plots (Schmelzkopf 2002, Smith and Kurtz 2003, Staeheli et al. 2003). Further research into societal benefits suggests that community gardens provide a sense of meaning and place, cross-cultural interactions and when surveyed, participants report a higher sense of safety and living adjacent to green spaces has a negative relationship with self-reported life stress (Okvat and Zautra, 2011). Other researchers corroborated these findings (D'Abundo and Carden, 2008; Hannah and Oh, 2000; Lawson, 2007; Macias, 2008; Roubanis \& Landis, 2007) and found that community gardening leads to a "stronger overall sense of community" (Draper and Freedman, 2010). In the case of Latino community gardens in New York City, community gardens "host numerous social, educational, and cultural events, including neighborhood and church gatherings, holiday parties, children's activities, school tours, concerts, health fairs, and voter registration drives" and help to increase social activism (Saldivar-Tanaka, 2004). Social scientists documented the effects of social capital in community gardens and how expanded networks affect situations outside of the gardens themselves (Glover, 2003, 2004; Glover, Parry, et al, 2005; Glover, Shinew, et al. 2005; Shinew et al., 2004).

Benefits literature continues into two broad categories: ecological and economic. The research into these categories are lighter than the social benefits but are integral to green infrastructure investment. Community gardens are found to increase ecological biodiversity (Colding 2006), offsetting the cost of environmental pollution (Rodenburg 2002) and attracting 
necessary pollinators to a city (Goulson, 2010; Osborne, 2007; Sirohi, 2015). Economic benefits range widely from increased property values (Rodbell 1991, Irwin 2002) and increased tax income (Voicu and Been 2008), to food security and job opportunities through the building of social capital (Glover, 2004).

\section{Studies Critically Analyzing Community Garden Impacts}

Despite these ecological, economic and societal benefits to community gardens, there is growing evidence of negative externalities to community gardens ranging from soil contamination in low-income areas, eco-gentrification, and an uneven distribution of benefits for community gardening. Studies of community gardens in post-industrial or near heavy industry zones have uncovered heavy metals and contaminants throughout the garden (Armstrong, 2000; Finnster, 2003; Kessler, 2013; Kim, 2014). In the cases observed, these contaminants (such as lead) were found in higher levels at community gardens than in other sites near the plot. This contamination of soil may undermine the health benefits associated with these urban gardens (Kessler, 2013; Kim, 2014). Those with lower political or social capital (Bourdieu, 1991) may not have the resources to socially mobilize on a community level to advocate for cleaner air or higher industry regulations on surrounding zones.

A growing body of critical literature indicates that in Denver, CO (Teig et al., 2009), Philadelphia (Meenar and Hoover, 2012) and Portland, OR, white gardeners outnumber people of color disproportionately to the demographic composition of those cities (Slocum, 2006). It is then argued that community gardens and urban agriculture in cities may unevenly benefit white and wealthy individuals (Hoover, 2013). Green subcultures such as farmers markets are argued to predominantly experience white values, and participation (Alkon and McCullen, 2010). This 
subculture then "creates a kind of insider ambiance, in which those who know the wider scene, who tend to be white, feel welcome while those who do not may feel excluded" (Alkon and McCullen, 2010, p. 949).

Portland is ranked amongst the "top ten cities in the US for urban farming" (Renner, 2016). The investment in sustainability has created a focus on green infrastructure and promoting sustainability practices (Mcclintock and Simpson, 2016). Portland city planners have focused on green and sustainable investment to attract high-income earners. Accordingly, Portland has been categorized as a "Green" and "Sustainable" city as planners have promoted sustainable development and cultivated the cities' conception of a progressive ecotopia. Yet, recent research has argued that "Portland's sustainability success are inequitably distributed" (Goodling et al., 2014). Portland's urban core has become more white and affluent while its outer east-side has become more diverse and poor. Investing in sustainability development has many benefits for a community and attracts individuals from all around the US, but can come at a cost.

\section{Urban Agriculture}

Urban agriculture is the cultivation, processing, and distribution of food in urban areas, and community gardens are loosely defined as a single plot of land gardened collectively. Community gardens can be outside of an urban area but are becoming more and more popular within the bounds of a city. Much of the research exploring the effects of urban agriculture tie together the effects of urban community gardens and urban agriculture. McClintock, (2018) argues that the negative impact of urban agriculture suggests that the more affluent group tends to monopolize the majority of benefits through a variety of mechanisms including establishing exclusionary cultures or raising costs that push out less powerful groups. Investing in urban 
agriculture may be exasperating gentrification through eco-gentrification and encouraging insider ambiance to create exclusionary spaces and subcultures that exclude minority populations with a negative stigma.

\section{Theory}

\section{Grounded Theory}

Grounded theory is a qualitative inductive research method that uses systematic methods and analysis when deductive theory is not available (Strauss, 1987). Grounded theory is the theoretical model chosen for evaluating the transcripts of the 17 black and African immigrant Portland gardeners because of the limited literature on barriers to community gardening and the significance of the population interviewed. Ideally, Grounded theory would have been applied to the methods and data gathering techniques. This study is dealing with pre-gathered data and thus is solely using grounded theory to evaluate the data and produce a guide for further studies and analysis. That paper has no specific hypothesis as to understanding community barriers as to allow the results to guide the analysis, the model (fig. 2), and to use the codes to identify further research recommendations.

\section{Eco-Gentrification}

The concept of gentrification was introduced in the US in the 1970s and has been widely researched since. From housing, economic, health and cultural gentrification arose a new term called eco-gentrification in 2009 "which I define as the implementation of an environmental planning agenda related to public green spaces that leads to the displacement or exclusion of the most economically vulnerable human population — homeless people — while espousing 
an environmental ethic" (Dooling 2009, 41). Gentrification is the arrival of middle-class individuals into a predominantly lower-class area, and eco-gentrification is a subsect of this concept in which an environmental agenda and implementation encourage the influx of middle-class individuals. Evidence of gentrification in Portland pushing out the racially diverse has been documented in studies of a community known as Albina in Portland (Ause 2016, Gibson 2007, Retail 2011). Albina is a community nestled slightly east of the urban core that once had the highest per-capita black population in Portland. The black population is lower today than it has been in the last 60 years. These communities are being displaced and pushed further and further east of 82nd (Goodling et al., 2014). Paired with research is evidence of eco-gentrification where Portland's green infrastructure investment is exasperating displacement (McClintock, 2018).

Scholars have since critiqued sustainability development as potentially exasperating displacement and not providing well-being for all the residence where green and sustainability initiatives are implemented (Bunce, 2009; Cucca, 2012; Dooling, 2009; Gould and Lewis, 2017; McClintock, 2018; Quastel, 2009; Wolch et al., 2014). Although community gardens have been around for quite some time, they can be perceived as a way to signal the formation of a green community while investing in sustainable infrastructure. Paradoxically, in the case of Portland, community gardens can result in exasperating gentrification by attracting middle-class whites and upholding barriers (intentionally or not) that often exclude people of color (McClintock, 2018). As pointed out by McClintock (2018), in 2012, the director of Portland's Bureau of Planning and Sustainability admitted that Portland's sustainability investment is rooted in as many entrepreneurial values as sustainability. 
"We're not doing it just to be altruistic. Part of the reason we're doing a lot of this is there's money to be made to be made, to be crass. . . .And most of these things are things we want to do to create better, healthier places, anyways. But by doing that, you create a place where people want to live and have businesses.” (quoted in D.M. Smith 2012).

\section{Barriers}

The barriers to community gardening literature is very light and generally resides at the meso-level. Researchers are commonly looking at community organization structure, interviewing community leaders or understanding how policy affects the formation and access to community gardens. There are extremely limited studies that focused on the barriers to community gardeners on an individual level and even fewer that addressed racial disparities or white spaces that often accompany community gardens in the Pacific Northwest. Due to this gap in the literature, this paper examines a study researching barriers to urban community gardening outside of Berlin, Germany by Becker and Von Der Wall (2018). Three community gardens were studied with the intent to identify and categorize barriers. They created the following chart that deconstructs barriers into two categories: primary and secondary which were found to affect both individuals and organizations. 


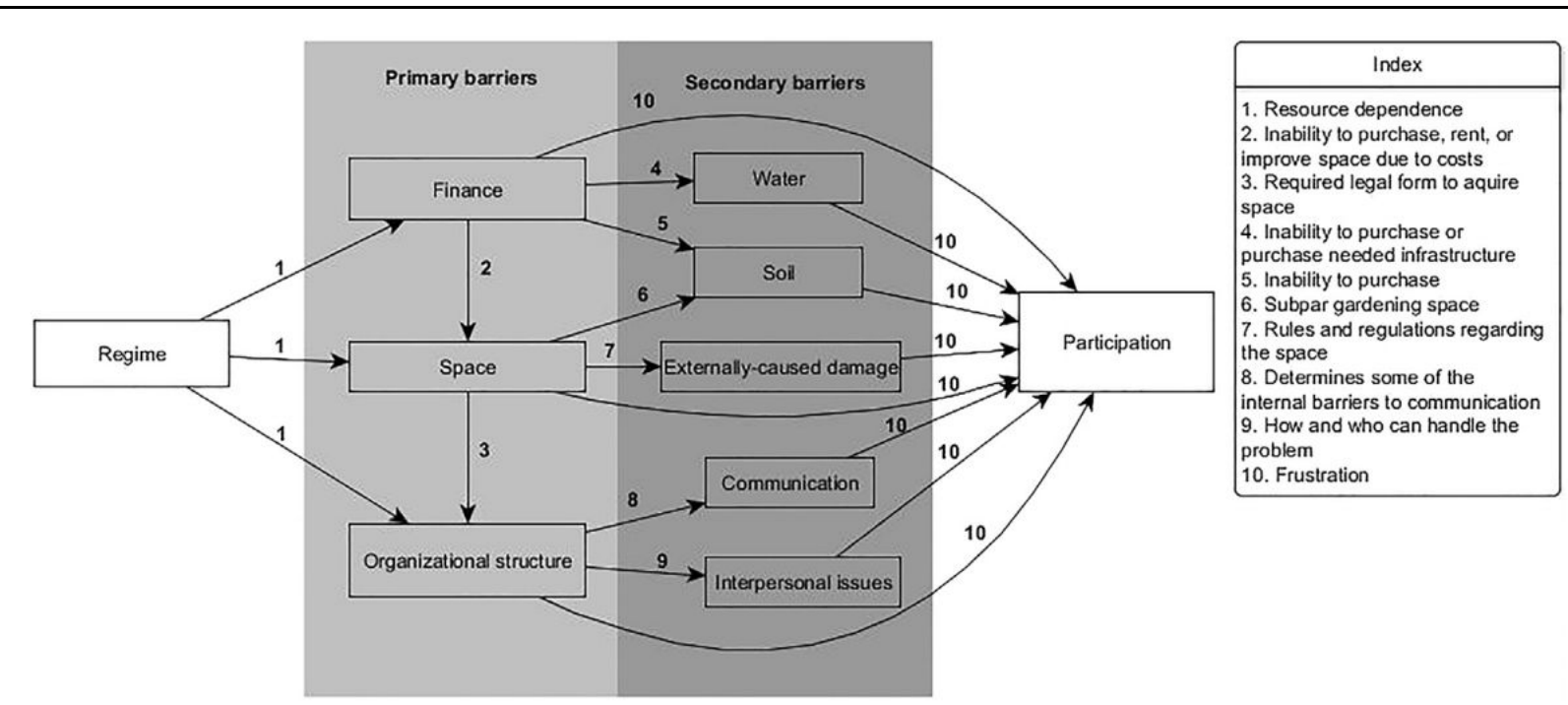

Fig. 1. Process tracing the process of how the barriers in urban gardening influence garden longer term sustainability.

\section{Becker and Von Der Wall (2018)}

Applying this model, Becker and Von Der Wall (2018) identified ways in which participation in community gardening is affected by barriers. Their findings suggest that financial, spatial and organizational structure are all interconnected and have relationships with the level of participation in community gardening. The focus of this study was on socio-economic and organizational barriers but did not span cultural or exclusionary barriers that were major themes throughout this qualitative analysis. I will modify and apply their framework when analyzing the barriers identified in the 17 interviews of black and African immigrant gardeners in Portland.

In a study of community gardeners in Richmond, VA, Jettner (2017) found in her sample that community gardens were largely racially segregated and community leaders suspected that this was due to "structural barriers (e.g. working several jobs) and general life circumstances (e.g. having children) that low-income people of color face”. Gentrification, historical trauma, 
lack of entrepreneurial opportunities, and the inability to secure one's harvest were additional disincentives that were cited by those same leaders as to why the gardens were not race or class diverse. Jettner points out that some scholarship indicates that minority community leaders who are aware of structural and cultural barriers can increase minority participation by having that knowledge (Ghose \& Pettygrove, 2014; White, 2011). It has been noted that some seemingly benign practices, such as erecting a fence, may signal an exclusionary space (Glover, 2004). Becker and Voon Der Wall pointed out that theft was not much of an issue in the garden that had a fence which implicates solving some barriers (theft) may encourage others (lack of an inclusionary space). The scholarship into barriers is limited and thus the reason for this paper. It is important to both build the framework for studying barriers and make the case that studying barriers is important for community leaders looking to implement social justice policies and encompass more people into the benefits of community gardens.

\section{Project Design}

The design of this paper is trifold. This paper is structured to 1) understand the literature pertaining to community gardening, 2) apply grounded theory to 17 semi-structured in-depth interviews gathered by PSU masters candidate David Billings (2018), and 3) create a barriers model to identify all the factors limiting community participation. Portland's government and population tends to vote and enact progressive laws that are often framed as sustainable, but Portland is not very diverse when compared to other major progressive cities (e.g. New York City and Los Angeles are less than 50\% white). Due to recent research into sustainability, gentrification and the unequal development of communities in Portland, there has been growing 
scholarship to suggest that not all populations in Portland receive benefits from sustainability investments or urban agriculture initiatives. Indeed, many minority groups are heavily gentrified and pushed further and further east of the city (Goodling et al. 2015, ). These concepts are theoretical centerpieces to this framework, but due to the lack of research on the barriers to community gardening, there is a vacuum when understanding the specific barriers decreasing participation.

Becker and Von Der Wall (2018) touch on the complexity of barriers and their relationships, but they leave out cultural barriers. This is probably due to the interviewees and data set that they were researching. This study looks specifically at black individuals in a city where $76.1 \%$ of the population is white. Although black Portlanders make up $6.3 \%$ of the population, $1.6 \%$ of the (approximately) 1,000 PPR plot holders are black, and all 17 of the interviews in this study are with black and African Portland residents. There is limited data for other community garden programs but their numbers are very low compared to PPR plot holders.

\begin{tabular}{|l|c|c|}
\hline \multicolumn{2}{|c|}{ Table 1: Race/Ethnicity for PPR community garden plot-holders (2016) compared to (2010) Census } \\
& Data Race/Ethnicity & \% of Portland population \\
\hline & & \\
\hline White & 69.5 & 76.1 \\
\hline Black/African American & 1.6 & 6.3 \\
\hline American Indian \& Alaskan Native & 0.3 & 1 \\
\hline Asian & 7.6 & 7.1 \\
\hline
\end{tabular}




\begin{tabular}{|l|c|c|}
\hline Native Hawaiian and Pacific & 0.2 & 0.5 \\
\hline Hispanic or Latino & 6.6 & 8.4 \\
\hline Other race & 2.2 & 4.2 \\
\hline Multi-racial & 4.4 & 4.7 \\
\hline Declined & 7.4 & - \\
\hline *Due to some overlapping categories, census total exceeds 100\% & \\
\hline
\end{tabular}

\section{Data Collection}

The data for this project was gathered using semi-structured, in-depth interviews of 17 black and African Immigrant adult individuals who participate in community garden spaces across Portland, Oregon. Participants were asked about their experiences in the gardens, both negative and positive, perceptions of the spaces and other gardeners, and the impact of these factors had on their activities, participation and overall experience. The in-depth interviews were semi-structured, following an interview guide and allowing for deviation. Whenever possible, the participants were allowed to lead the interview, only referring to the guide as needed. The final questions in the interview requested information on the racial dynamics of their garden and any changes they would make if they were able to. The gardeners were from 10 gardens across Portland.

Participants were recruited using a purposive convenience sampling approach and outreach including publishing a newspaper ad, emailing community garden managers, and snowball sampling. Several participants were also recruited in person during periods of 
observation at some gardens. The gardens of interest were identified using Portland demographic data available through the PPR community garden program. Other gardens outside of the PPR system were identified as potentially having multiple black or African Immigrant community gardeners.

Informed consent was granted by all participants. All interviews were assigned a pseudonym digitally recorded and fully transcribed by a researcher or research assistant. The interviews ranged in length from 21 to 70 minutes, with an average of 41 minutes. Six of the interviewees identified as male and 11 identified as female and the average age of the group was 46 years old. Eight participants had a college or graduate degree, and six had some college. Only three participants had less than high school or high school.

\section{Coding and Variable Identification}

The frames applied when creating the codes began with a collaborative effort to predict the barrier variables affecting an individual after multiple pass-throughs of the transcriptions. As the coding process proceeded, codes were altered and added to best formulate more accurate categories of barriers. Barriers were listed in three broad categories that are closely interrelated to each other. Each category has its own sub-categories that were coded and applied to the transcripts.

Motivations are push/pull factors that constitute the allure of community gardening. They are conceptually understood as the positive to the negative barriers which prevent community garden participation. Even if the motivation is high to garden, barriers may make it impossible or too difficult. Thus the barriers were broken down into three categories for easy conceptualization and manipulation: structural, social and cultural. 
Structural barriers in the context of this paper can be policies, practices, locations, and norms established on an organizational level that favor an advantaged group while systematically disadvantaging a marginalized group. Under this umbrella falls the effects of gentrification through many different avenues. Barriers on this level are perhaps the most accessible for city planners or community leaders to address as they include information, cost, rules/bureaucracy and proximity to the community gardens. These concepts are not mutually exclusive and often require the absence of these barriers for an individual to access their local community garden.

Social barriers in the context of this paper refer to any obstacles one may experience pertaining to family, socio-economic status or feelings of safety on an individual or group level that discourages participation in community gardening. This category is broad and made up of time, kids/family, safety and theft/vandalism barriers that influence participation. This category fills the grey area between cultural barriers and structural barriers.

Cultural barriers in the context of this framework are any impediments or difficulties caused by cultural differences. This can include any difficulties arising from negative social stigma relating to race, cultural norms or languages. There was difficulty from the respondents in articulating these barriers past feelings they had about spaces where they did not feel welcome. Obvious cultural barriers include language or overt racism, but harder to quantify and more subtle cultural barriers span a feeling of ostracization, a feeling of non-belonging due to race, or feeling like the participants were always watched when in white spaces. 
$\underline{\text { Results }}$

The results of the analysis are categorized in a theoretical framework that captures many of the structural, social and cultural barriers that must be weighed against motivations to calculate the likelihood of participation.

\section{Barrier Variables Affecting Likelihood of Participation in Community Gardens}

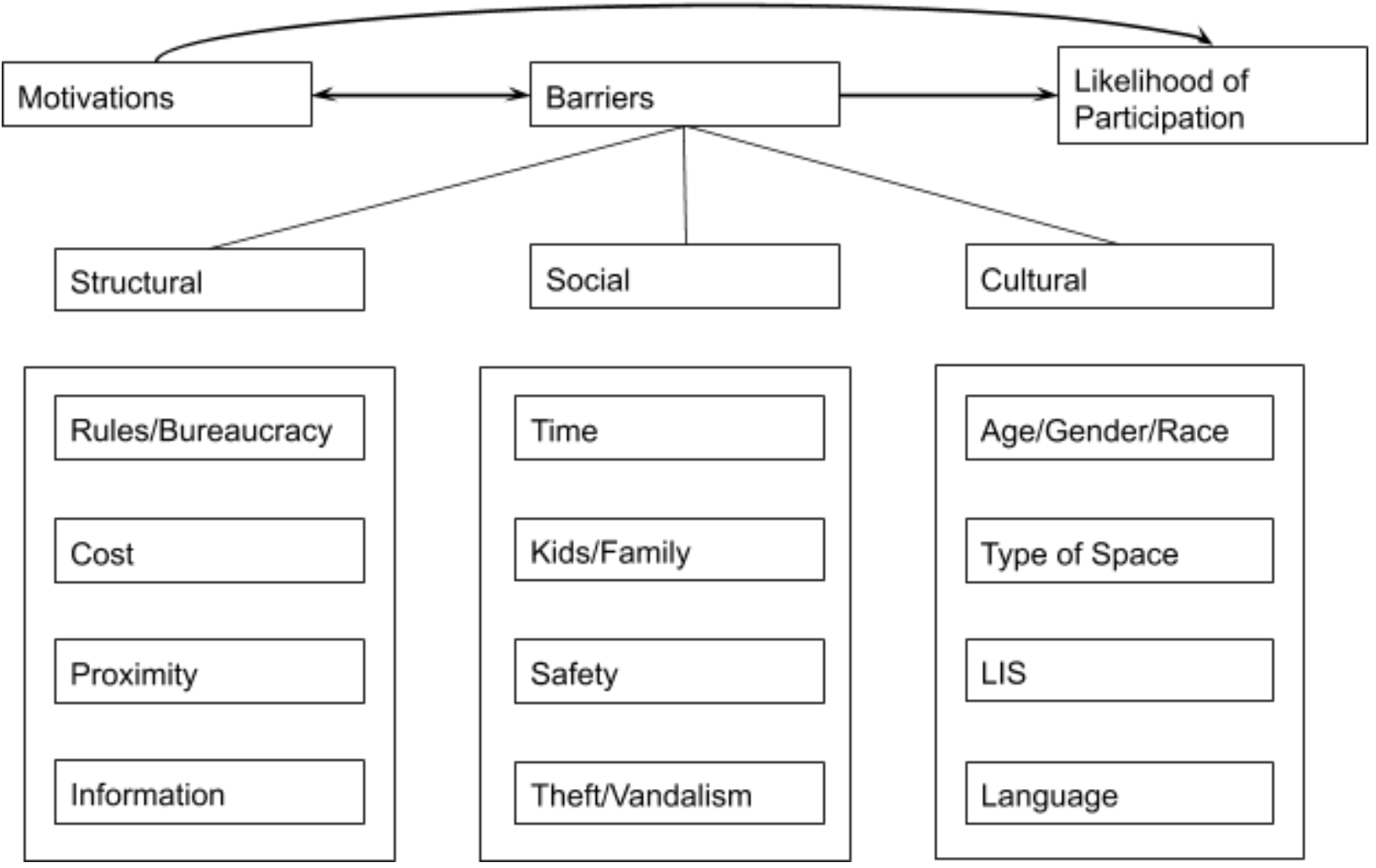

Fig. 2. Model of barriers affecting the likelihood of participation in community gardens. 


\section{Structural Barriers}

Informational barriers. A primary barrier to gardening is access to information, and under this umbrella falls understanding and navigating the application process, understanding hierarchies, availability of plots, norms, rules or even knowledge of how to participate. This includes the available information individuals receive from information holders concerning their local community garden and the ease in which a program can be applied for. Churches and community organizations often publicize or run community gardens but this can be a limiting factor in itself. For example, depending on where information campaigns to increase garden participation are being disseminated, location will factor into which groups become aware of said program. In Portland, scholarship programs are available for low-income gardeners and navigating the scholarship program can be resource-intensive and require access to knowledge that is not widely disseminated amongst disadvantaged groups.

Individuals interviewed commonly reported not hearing about how or where to garden, this barrier is one of the first structural barriers faced by Portland gardeners. Subsequently, with sufficient knowledge of where to garden and the process of applying to gardens, gardeners reported frustrations learning the rules and navigating the sometimes complicated programs available to them. Some gardeners reported a lack of information shared by garden managers, even when they persistently requested access to chain emails or monthly newsletters. Many gardens in Portland throw weekly, monthly or yearly events and use different strategies to spread the word. If the information dissemination infrastructure is lacking, this may be a major barrier for gardeners and may increase feelings of isolation, as explained by a respondent under the pseudonym Lisa. 
"Lisa: And also, the communication. So I get the communication from Portland Park and Rec, but I've gotten no communication from this actual... from the Garden Managers. So, I mean they post... like they post if there's a potluck or something but I have a sense that people know each other here and they... I don't know if they are just friendly with each other or... Like I know some people are part of the same family but it seems like, I know there's an email list or there're emails that go out. They're like, "Oh, you didn't get that email?" I'm like, "no, I didn't get that email." So um I think if people take on the roll of like manager, if you're gonna volunteer for that you need to make sure you're including everybody."

Proximity barriers are any restrictions on the access of community gardens based on the proximity or location of the garden. These barriers are closely tied with gentrification as people with low-income are pushed further and further away from community gardens. Distance from community gardens can make participation progressively more difficult. Transportation infrastructure serves as a factor that either can compound proximity barriers or alleviates them as access to gardens can be restricted by bus routes, parking availability, proximity to public housing, or the physical location of the garden.

"Albert: There's public housing four blocks away. Many of those folks- if you get somebody to run it that enjoys it, where it's not a problem- if they have to come across town for a four-hour job twice a week you're not going to come across town for a four-hour job twice a week. But if it's close by it's not that hard."

Cost barriers include any out of pocket expenses required to participate in community garden programs. This can include the financial burden of living near a garden (see lit review: Community Gardens and Property Values), garden supplies, tools, plots, and other fees or 
expenses required to be covered by gardeners. Plot rentals can range anywhere from $\$ 10-\$ 200$ a year, yet a more subtle expense may be living in a neighborhood where property values rise due to the establishment of a community garden (Voicu and Been 2008). This sort of eco-gentrification is a hidden cost to Portland's green infrastructure (McClintock, 2018) and reflected in the concerns of the sample.

"Lisa: I think you have to have the time. Like, I know people who are open to gardening but they don't, they literally do not have the time. You have, I mean, more Black folks are towards the lower end of the income scale than the higher end so you usually working couples if you're not, if you're in a relationship. They're usually both working and you add kids to that, then you add rising rents to that."

Seed and tool sharing programs help offset the costs of items required to garden, where scholarships can help eliminate the cost of the plot rental. These programs require an understanding of how these systems work and where to access assistance, yet costs and resources were common concerns for the interviewees.

"Donna:. . .I see the contradiction here is that if you will- if you want to have a, like a garden, that takes time and resources but if you have to work to get economic power for yourself for just basic necessities then that leaves you kind of limited time for a garden, right. And so you have to kinda prioritize."

Rules and bureaucracy were commonly referenced barriers that gardeners expressed frustration over. This category spans all rules and regulations that require or restrict actions access to and/or once a member of a community garden. PPR's waiting lists were sometimes so 
long that they frustrated some of the gardeners interviewed, so much so that in some cases, they found or founded other garden organizations.

"Jay: ... I tried getting into one of those... things [PPR plots] and reserved my name into one of the plots but they basically said you have a three year waitlist, so...

Billings: Especially for one that's anywhere near where you live.

Jay: Yeah, I mean the closest one to me was sunny side or wherever. It was like Belmont and something. Belmont and 25th or something like that. That was like the closest one so I didn't even, I just gave up on that idea... a long time ago.” - Jay

Many community gardens have minimum volunteer hour requirements, in which participants have to come in and volunteer their time to the community garden. A common frustration was expressed over the enforcement of strict rules by garden managers or other gardeners, which was perceived as "policing". Some gardens had a "three-strike" policy that involved plot maintenance. Plots with excess weeds would receive a warning and after three warnings, the plot holders were evicted. Individuals who were struggling with life circumstances reported feeling ostracized or controlled by garden managers and other gardeners who were trying to enforce legitimized or non-legitimized normative rules.

"Henry: Well we kind of talked about it before. I think the policing of people just trying to grow food. That's probably a major factor. I don't know if they cost anything for Portland Parks and Rec but I feel like if you're in survival mode and you're working, you're trying to make 
ends meet, having a community garden could be the last thing on your list. If you're just trying to get your family stable, I mean even if it is a benefit like I could save money or things like that, you may not be thinking about that."

Once an individual learns about the program, applies, gets accepted, pays for all expenses, they then have the next steps of navigating localized rules, hierarchies and cross-cultural relationships.

Social Barriers

Time barriers are any constraints put on a gardeners life due to a lack of available opportunities to garden. They were one of the most referenced barriers as to why, previously, individuals could not directly participate when motivations were high. It was also highly connected with other barriers and often would be referenced in tandem with family, cost or proximity barriers. I argue that this is evidence of how gentrification can put restraints on individuals attempting to participate in community gardening as increased barriers in other facets of one's life can influence the time ability or priority of community garden participation. Installing environmental and community infrastructure may have been an externality that pushes out the individuals who the infrastructure was intended for. This combination of structural and social barriers, I argue, can be extensions of eco-gentrification and take the form of restrictions on an individual's time garden participation.

"Billings:... Do you have any insight as to why that [reason for lack of participation] might be?

Lisa: People don't have time. 
Billings: Just time, yeah.

Lisa: It's a lot of time. It is A LOT of time. I mean the weeding and the having to physically be here every day to water, buying things, and... It's a huge project to take on so you really have to be committed. It's much easier to just a Farmer's Market and buy what you need."

Children were rarely mentioned by the sample, although this may due to survivorship bias - in that those who are not gardening and being interviewed could not garden due to the life constraints of having children. Only a few of the interviewees had children young enough to provide constraints to their participation in community gardening, and the ones with older children (older than toddler and teen) brought with them to garden. When asked, they felt very positive about the reported lessons that gardening offered their children. Constraints on time due to family and children dynamics puts limitations on activities which then changes the question to prioritization, and what an individual can feasibly prioritize. Mentioned in the transcripts is that it may not be feasible for a family to invest in community gardening if other structural or cultural barriers compound and then prohibit them from doing so. Family composition and parental responsibility was a barrier understood by the gardeners.

"Sara: She is newer. The other person has a small child and they haven't been here as much because trying to manage, with a little one, and then garden is difficult. It is difficult. So I haven't seen too much of him this year at all."

Safety barriers are any concerns around comfortability in or around a garden. They were more of a concern for community gardens in areas with a higher density of individuals living with a low socioeconomic status. Some of the interviewees considered not gardening due to 
growing concerns of safety in their garden and reports of unsafe individuals usually associated with people experiencing homelessness near or on the way to the garden.

"Lisa: Yeah and then on the far North end of that path at the school there are now encampments in there too. And we want to be open-minded and now we have a bathroom so we had to lock the bathroom because people were using it and the water gets used. I think I am getting to the point where I am concerned about safety. The last few years there have been a few people who are in the garden all the time and I offer whatever I have to them... But I... I feel like it's turning now to feel a little less safe. I actually was just thinking maybe I should stop gardening. Just had that thought last week.”

It's widely reported that high gentrification raises the costs of living and increases the population of displaced individuals (Elliott-Cooper et al., 2019), and alongside Portland's history of gentrification is its growing displaced populations, which ranks as one of the highest rates in the US (U.S. Department of Housing and Urban Development, 2018). When installing community gardens in low-income areas flanking highly gentrified areas, those participating in community gardens can experience higher levels of safety concerns if proper safety protocols are considered (lighting, locks, gates, etc). The same protocols that may make a location feel gated or exclusive, further complicating the issue.

Theft/Vandalism reports were frequent throughout both interviews conducted and other studies similar to this one (Becker and Von Der Wall, 2018). The instances ranged from petty theft of produce or gardening supplies to vandalism and destruction of property and garden plots. As noted by Becker and Von Der Wall, these instances may be reduced by maintaining a gate, but having locked gates were reported as maintaining a feeling of exclusion. Safety protocols 
instituted by garden organizers often precipitated to policing by other members and garden leaders, which occasionally created a source of tension between those who felt the gates and rules were ineffective or pedant. One interviewee noted feeling as if they had to be very careful to be seen as following all rules. They were hyper-aware in how they interacted with other gardeners because they felt they would be incorrectly blamed for theft or rule-breaking just because they were the only black gardener in that garden.

\section{Cultural Barriers}

Language is a powerful barrier in urban cities as many different communities are living in one space. Language barriers can be difficult to surmount as it was referenced multiple times by the Africans interviewed. In one case, an individual shared no language with other gardens and they frequently found themselves breaking rules and causing frustration to other gardeners. Some gardeners found themselves trying to communicate via a series of impromptu sign language in attempts to convey messages to other gardeners. I speculate that this may increase isolation, restricting much of the social benefits that accompany community gardens.

Lack of an Inclusionary Space (LIS) is a barrier that is difficult to measure or report, but it was the most frequent concern by the respondents. Half the sample had at least one reference to a feeling of not belonging that ranged from a sense that they were being watched all the time (which was very common), to maintaining a hyper-vigilance in managing their impressions to avoid negative social stigma, microaggressions or simply feelings of unfriendliness. Microaggressions were reported by the interviewees who stated frustration over garden members actively trying to change the way they gardened, sometimes very bluntly telling 
them that they need to do something different within the bounds of their own plot. Two excerpts when answering a broad question relating to "negative experiences" went as follows:

"Tamica: Um, the negative experiences that stand out honestly have been, you know folks giving us looks, um being in the garden in that area that's really- just really white."

And...

"Donna: It's almost like, even now, when you walk up and down the street and you see a white person it's almost like they look at you with disdain, like with indifference, like what are you doing and it's like excuse me?”

This feeling of being watched was corroborated by gardener Andreka who explained how she felt like she had to be careful not to give the wrong impression so she is not stigmatized based on race. . .

“Andreka: Yes. So... with me, it's like you really have to be on your Ps and Qs. You know, make sure that you go above and beyond to make sure that things are put back. It was just a lot. I didn't want it to be like we have black folks in here and now the tools are coming up missing and this that and the other and that was always in my mind. So I wanted to make sure that wasn't the experience."

Zawiya elaborates on exclusionary comments that can affect interpersonal relationships “Zawiya: I wouldn't say they're not inviting. I would say that- I mean this is gonna sound like a pretty harsh rebuke cause people just don't want to be around white people who want the discussion, the produce, the culture to be about white things. Here's an example: In the late fall I plant collard greens and mustard greens for my Thanksgiving meal and I constantly get the question, "Well Kale-" This happened to me the other day, that someone said, "oh that's not a 
part of the Thanksgiving tradition" and I'm like "get out of here with that." So those kinds of like little things where people would just rather not- not in their healing time. They don't want those kinds of intrusions into your space. So it's not that their unwelcoming, it's just... their undesirable."

Considering the LIS concerns being a consistent theme amongst the interviewees, I argue that this may be one of the largest barriers to people of color trying to garden in these spaces in Portland, which may help to understand the lack of black and African immigrant participation. Due to the subtlety of these interactions that cause these individuals to not feel welcome, it can be more difficult for organizations and leaders to institute policies that provide for an inclusive cultural space. These difficulties can be compounded if the individuals making the policy or advocating for change do not share culture or similar experiences in these spaces.

The type of space is significant in the context of previous literature. Other studies found that community gardens were highly segregated (Jettner, 2017). This is also common in Portland plots, too. While there are a handful of organizations that provide community gardens for black or African immigrant gardeners, the majority of gardens in Portland are primarily white and this can make it difficult for people of color looking to garden in a community where they are not seen as an outsider. The concept of white spaces was a thematic concern in the interviews, with gardeners commenting on the discrepancies of white spaces compared to black spaces:

"Andreka: Even in Northeast where you may have spaces where you can garden, it's not inhabited by Black folk. It's inhabited by caucasian folk. Um, where you can have an apartment building or whatever it's like, you know we don't- we don't want to downgrade the property so you cannot garden on your property. It has to be kept, it has to be this. But you can see that same 
property a couple of years later and you have a bunch of Caucasian folks and low and behold they're gardening."

"Donna: I went to the Garden, yep, because I actually lived across the corner from it so when I walked my dog I would see it and take my grandchildren around there. And I went into it a couple times, you know, talk to the people that were there and I... don't know, it just, since the whole gentrification it always seems like the new people that have moved in are... what's the word I want to say, disrespectful, unfriendly, and just taking over. And not friendly to us and almost hostile.”

"Cherice: And then also you don't- I mean we met with someone just yesterday and she was like most of the people that do this gardening project are young white women. I mean people have to be able to relate to you if their in a space where they don't necessarily see reflections of themselves or feel welcome, they're just gonna be like, I'm not gonna go do that. I'm not gonna take my time to do it and maybe the community garden's out of their way."

Multicultural social benefits of community gardening are unlikely to happen if gardens are culturally and racially homogenous. In Portland, there are two black garden collectives that this study did not span. I'd recommend further research into nonprofits that sustain high levels of participation by people of color to better understand what motivates and discourages group participation.

Age, gender and race barriers is a broad barrier category that attempts to encapsulate the reported age, gender and race differences that were specifically mentioned as to why individuals were dissuaded from garden participation. In some cases, the perception of a frequency of white spaces discouraged young black gardeners from participating because they 
reported not feeling that gardening is something their generation or race does. One gardener captured this notion when reflecting on they did not see more black young gardeners:

"Donna: The negative thing that I think about it is would I talk about the culture piece and how for young people gardening isn't sexy. It isn't like the popular thing right. It feels more like work versus it's a value it's a benefit."

The average age of gardeners tends to be older (40s and 50s) which then has an effect on a gardeners ability to make friends and socialize. Other gardeners reported feeling excluded because only gardeners they saw in their local garden were "middle-aged white women". This category can be a barrier, as it can signal to those looking inwards that this is not an activity for their group, but it can also be beneficial as it may increase a gardeners social capital by expanding their network.

\section{$\underline{\text { Discussion }}$}

One can imagine the difficulties of an individual who has high motivation to garden but has a series of progressively more convoluted barriers to navigate through to garden. From stringent bureaucratic rules, lack of funds, time or familial obligations to cultural discrepancies that makes gardening in a communal space more difficult or near impossible for less powerful groups. Certain minority populations may disproportionately experience more difficult barriers precipitating into a lack of participation and creation of exclusionary spaces adding to the negative effects of gentrification. Discrimination, feelings of being watched and being an outsider were a consistent theme amongst participants and may indicate the reason for low black and African immigrant community garden participation in Portland. 
Some studies suggest that many community leaders are aware of the effects of gentrification but are at a loss with what steps to take against it (Jettner, 2017). There is evidence to suggest that community gardens can help assuage the negative effects of gentrification, but in some cases exasperate them. This study bridges the gap between the benefits of community gardening and the critiques that elucidate some of the stratified systems of green infrastructure. I argue that it is important to understand how this exasperation occurs and what prevents low minority participation in community gardens. The model suggests that in the case of Portland, cultural barriers may be very significant when determining the likelihood of participation and should be considered by city planners, community organizers and gatekeepers looking to invest further into green infrastructure. Further research into surmounting structural, social and cultural barriers to encourage minority participation in community gardens is required.

\section{The Significance of the Sample}

Black (including African immigrants) gardeners make up 1.6\% of the roughly 1,000 plot holders through Portland Parks and Rec (totaling 16 Black/African American plot holders through PPR). The 17 interviews were with individuals from PPR gardeners and other organizations that we do not have data on, and for the sake of anonymity, those programs will not be named. Those community gardening programs that reach minority populations do not make up a large percent of the urban gardeners in Portland. The fact that there are so few black gardeners in Portland and the sample interviews reached 17 respondents means that this small sample size is relatively significant. Although these interviews reached a significant portion of Portland's black gardeners, the model and analysis are cognizant of survivorship bias - a bias in 
which one may over-weight the experiences of those who made it through the barriers and ignore the possible experiences of those who cannot and do not garden.

\section{Barrier Terminology}

I decided that the social barriers category disconnects cost and socioeconomic status because of the levels at which these concepts operate. Structural barriers are more of macro-level measurement, focusing on organizational and governmental influences, whereas social barriers are intended to measure meso and below barriers that fall out of the cultural barriers umbrella. This includes family composition, children, job type, class, free time, feelings of safety, destruction of property and non-culture related barriers. Cultural barriers are similarly on the meso and micro-level scale, but they involve race, age, gender, customs, interactions, roles and behaviors related to all of the variables. Social barriers and cultural barriers would be more complicated to address by community organizers, whereas structural barriers, I theorize, is simpler for policy or organizational action to address due to the type of power harbored by structural organizations. For example, it may be easier for a community organizer to reduce the cost (structural) of participation, but more complicated to try and address the people of color feeling stared at or feelings of ostracization (i.e. cultural barriers) reported by black gardeners.

\section{Variable Reasoning}

The reasoning for the variables of age, gender and race barriers arose out of 1). age, race and occasionally gender were mentioned as relevant factors by the participants, and 2). because previous scholarship notes that age, gender, and race participation varies widely amongst varying cultures. Perhaps this is due to age/gender/race roles in the communities and the presence of other cultural, social or structural barriers that interplay with these factors. In a leading study in 
New York (Krasny and Saldivar-Tanka, 2003), of the Latinx community, 90\% of gardeners and garden members interviewed were Puerto Rican, and only in two of the gardens researched did female gardeners outnumber male gardeners (with 7 of the gardens maintaining $95 \%$ male gardeners). Hanna and Oh (2000) found that $75 \%$ of African American and white gardeners were female in Philadelphia. Similarly, Krasny and Saldivar-Tanka found that "senior citizens are the most active gardeners. ..". This question of roles in gardening spans the breadth of the study, however, this can fall into the framework of barriers weighed against motivations.

Because of the repeated concern of the respondents found in the code "Lack of an Inclusionary Space" in this significant data set, I argue that in the case of Portland, culture plays a considerable role in increasing or decreasing the likelihood of garden participation. Some scholarship indicates that minority community leaders who are aware of structural and cultural barriers can increase minority participation by having that knowledge (Ghose \& Pettygrove, 2014; White, 2011).

\section{Implications for Gentrification}

Gentrification and eco-gentrification are widely researched in Portland. Figure 2 explores the present barriers decreasing participation in community gardening, assuming that motivations to gardening are near that of other cities around the US. In the data, I did find evidence of gentrification as it was reported by the interviewees that their communities were changing around them. These reports also mentioned rising rent costs and an influx of people experiencing homelessness. These testimonies tie into the broader conversation of gentrification and displacement in the discourse community (Gibson, 2007; McClintock, 2018; Goodling et al., 2015) 


\section{Further Research Into Barriers to Community Gardening}

I would recommend research to focus on how to assuage the effects of gentrification and how to encourage sustainable investment and green infrastructure without exasperating eco-gentrification. Perhaps community gardens run by people of color, for people of color, in low-income neighborhoods would allow rapidly gentrifying communities to expand their social capital, and allow access to the benefits found in community garden literature. These benefits may then offset some of the damages from displacement and gentrification. I would recommend research that specifically looks at how community gardens can, under the correct auspices, provide a bulwark against gentrification.

Many questions arose during the breath of this research. Although the barrier model (fig. 2) was created with the hope of serving as a template for further research, I would recommend an expansion of the model and the definitions, as needed. Each community is unique in its overlapping structural, social and cultural framework that defines varying motifs of said society. Respectively, I'd recommend an expansion of terms and definitions, especially in respects to CRT and how it applies to barriers to community gardening.

Enough evidence was identified to suggest that cultural barriers are a large factor in participation among black Portlanders. I argue that more research is needed to identify why this is the case and, most importantly, what can be done on every level to help dispel these barriers. In the case of one of the respondents, this community organizer threw a party at a newly established garden site. The participants were -

“. . almost all Black, which is so cool you know, just having a lot of Black people there at a farm, kicking it with like a bunch of- like the background of just food growing and people 
drinking and smoking and having a good time. Music and, you know we just were- it felt like exactly what I had hoped for you know, bringing consciousness to like what it is this land is all about."

This corroborates previous literature that suggests that community organizers of color can help overcome these barriers (Ghose \& Pettygrove, 2014; White, 2011). A sentiment held by the interviewees

"A lot of these people aren't even targeting African Americans. I don't know if they can get more grants or what not if their working with immigrant families. I don't know if they feel like their success rate would be more because those immigrant families are more- like they would probably actually utilize the space without as much, you know like pushing or whatever. I think the African American culture, you need to have somebody who's engaging them and helping them with technical assistance more and so that just adds to peoples- whoever's managing the garden, that just adds to their workload. .."

I recommend further research into exactly what type of cultural barriers prohibit or discourage participation in community gardening, and I would like to emphasize further research into how to surmount structural, social and cultural barriers.

\section{$\underline{\text { Limitations }}$}

There is much more research that needs to be done on barriers to community gardening. Grounded theory is applied to the literature gap that exists on theoretical explanations of barriers and their effects on participants. This study attempts to lay the groundwork of analysis and applies said analysis to Portland, OR unique socio-economic and cultural makeup. Further 
research is needed on how to surmount the barriers or increase motivations. This study does not cover motivations, which can be a major factor in the likelihood of participation.

It may be significant to note that the Lack of an Inclusionary Space (labeled as LIS in fig. 2) was the highest reported category in the interviews, and surprisingly, there was over double the frequency of Lack of Inclusionary Space than any other individual category. This may be due to the formulation of the questions and prompts from the interviewer, but Becker and Von Der Wall did not mention cultural barriers, which may be due to the nature of their questions, prompts, design or population interviewed. I would recommend future research into identifying and evaluating cultural barriers through Critical Race Theory (CRT) (Delgado et al., 2017) which may help to better understand racial interactions between gardeners. Although on the periphery of this paper, CRT can help to understand these dynamics through theories on discrimination, the white gaze, stereotypes, stigma, and double-consciousness. These factors may have significant effects as to why black individuals are not participating in Portland community gardens. Due to time and data constraints, this paper does not span a CRT analysis of the results, but instead, creates a framework in which community organizers and social scientists may identify the issues within their unique community.

\section{$\underline{\text { Conclusion }}$}

If community gardens continue to grow in popularity and their effects are as positive as the research indicates, then finding ways to disassemble inequitable barriers is highly important to assuage the negative externalities of green infrastructure investment. Eco-gentrification is a rising issue for urban communities, and Portland is at the forefront of 
many of these negative effects. Community gardens stand to increase the social capital and the food security of vulnerable populations which may help community organizers to address displacement or many of the negative effects disproportionately bearing down on low-income communities. Due to a convergence of structural, social and cultural barriers, black and African immigrant populations are underrepresented in community gardens throughout Portland, OR. To address this, community organizers could promote people of color to positions of power who are aware of these barriers impeding community garden participation. Research into barriers to community gardening is relevant to any conversation revolving around bridging the gap between sustainability investment, green infrastructure and the equitable distribution of community garden benefits. 


\section{$\underline{\text { Works Cited }}$}

Alkon, A. H., and Agyeman, J. (2011). "Cultivating food justice: Race, class, and sustainability” (pp. 1-20). Cambridge, Massachusetts: MIT Press.

Alkon, A. H., and McCullen, C. G. (2010). "Whiteness and farmers markets: Performances, perpetuations... contestions?" Antipode, 43(4), 937-959.

Armstrong, D. (2000). “A survey of community gardens in upstate New York: Implications for health promotion and community development." Health and Place, 6(4), 319-327.

Ause, C. (2016). "Black and Green : How Disinvestment, Displacement and Segregation Created the Conditions For Eco-Gentrification in Portland's Albina District, 1940-2015. Portland, Or.” Portland State University.

Becker and Von Der Wall. (2018). “Tracing regime influence on urban community gardening: How resource dependence causes barriers to garden longer term sustainability." Urban Forestry \& Urban Greening, 35, 82-90.

Bicho, A. N. (1996). “The simple power of multicultural community gardening.' Community Greening Review 5: 2-11.

Billings, David. (2018). "White Space, Black Space: Community Gardens in Portland, Oregon.” Portland State University.

Bourdieu, Pierre, 1930-2002. (1991). "Language and symbolic power.” Cambridge, Mass. Harvard University Press,

Bunce, S. (2009). "Developing sustainability: Sustainability policy and gentrification on Toronto's waterfront Local Environment”, 14, pp. 651-667 
Colding, Johan, Lundberg, Jakob and Folke, Carl. (2006). "Incorporating Green-area User Groups in Urban Ecosystem Management.” AMBIO - A Journal of the Human Environment; Aug2006, Vol. 35 Issue 5, pp. 237-244.

Cucca, R. (2012). “The unexpected consequences of sustainability. Green cities between innovation and ecogentrification" Sociologica, 6 (2)

Delgado, Richard and Jean Stefancic. (2017). “Critical Race Theory: An Introduction”. New York: NYU Press.

Diaz, Webb, Warner, \& Monaghan. (2018). "Barriers to community garden success: Demonstrating framework for expert consensus to inform policy and practice". Urban Forestry \& Urban Greening, 31, 197-203.

Dooling, Sarah. (2009). "Ecological Gentrification: A Research Agenda Exploring Justice in the City.” International Journal of Urban and Regional Research 33, no. 3 : 621-639.

Draper, Carrie, and Darcy Freedman. (2010). "Review and Analysis of the Benefits, Purposes, and Motivations Associated with Community Gardening in the United States”. Journal of Community Practice 18(4):458-492.

Elliott-Cooper, A., Hubbard, P., \& Lees, L. (2019). "Moving beyond Marcuse: Gentrification, displacement and the violence of un-homing." Progress in Human Geography.

Faber Taylor, A., Kuo, F.E., \& Sullivan, W.C. (2002). "Views of nature and self discipline: Evidence from inner-city children.” Journal of Environmental Psychology, Special Issue: Environment and Children, 22, pp. 49-63. 
Finster, M. E., Gray, K. A., \& Binns, H. J. (2004). "Lead levels of edibles grown in contaminated residential soils: A field survey." Science of The Total Environment, 320(2-3), 245-257. doi:10.1016/j.scitotenv.2003.08.009

Ghose, R., \& Pettygrove, M. (2014). "Urban Community Gardens as Spaces of Citizenship." Antipode, 46(4), 1092-1112.

Gibson, Karen. (2007). “Bleeding Albina: A History of Community Disinvestment”, 1940-2000. Transforming Anthropology, Volume 15 (1).

Glover, Troy. (2004) "Social Capital in the Lived Experiences of Community Gardeners", Leisure Sciences, 26:2, 143-162

Goodling, Erin, Jamaal Green, \& Nathan McClintock. (2015). “Uneven Development of the Sustainable City: Shifting Capital in Portland, Oregon.” Urban Geography 36(4)504-527.

Gould, K.A. Lewis, T.L. (2017). Green Gentrification: Urban sustainability and the struggle for environmental justice Routledge (2017) 182

Goulson, D.; Lepais, O.; O’Connor, S.; Osborne, J.L.; Sanderson, R.A.; Cussans, J.; Goffe, L.; Darvill, B. (2010). "Effects of land use at a landscape scale on bumblebee nest density and survival.” J. Appl. Ecol. , 47, 1207-1215.

Guthman, Julie. (2008). “'If They Only Knew': Color Blindness and Universalism in California Alternative Food Institutions." The Professional Geographer 60(3):387-397.

Hoover, Brandon M. (2013). "White Spaces in Black and Latino Places: Urban Agriculture and Food Sovereignty.” Journal of Agriculture, Food Systems, and Community Development 2(4):109-115. 
Irwin, Elena, G. (2002). “The Effects of Open Space on Residential Property Values. Land Economics”, Vol. 78, No. 4 (Nov., 2002), pp. 465-480

Jettner, Jennifer. (2017). “Community gardens: Exploring race, racial diversity and social capital in urban food deserts." Virginia Commonwealth University.

Kessler, R. (2013). “Urban gardening: Managing the risks of contaminated soil.” Environmental Health Perspectives, 121(11-12), 326-333.

Kim, B. F., Poulsen, M. N., Margulies, J. D., Dix, K. L., Palmer, A. M., \& Nachman, K. E. (2014). “Urban community gardeners' knowledge and perceptions of soil contaminant risks.” PLoS ONE 9(2), e87913.

Kuo, F.E., \& Sullivan, W.C. (2001). "Environment and crime in the inner city: Does vegetation reduce crime?" Environment \& Behavior, 33(3), pp. 343-367.

Macias, T. (2016). "Ecological assimilation: Race, ethnicity, and the inverted gap of environmental concern.” Society and Natural Resources, 29(1), 3-19.

Malakoff, D. (1995). “What good is community greening?” Community Greening Review 5: $4-11$.

McClintock, Nathan, Dillon Mahmoudi, Michael Simpson, Jacinto Pereira Santos. (2016). "Socio-spatial differentiation in the Sustainable City: A Mixed-methods Assessment of Residential Gardens in Metropolitan Portland, Oregon, USA." Landscape and Urban Planning 148:1-16.

Nathan McClintock. (2018). "Cultivating (a) Sustainability Capital: Urban Agriculture, Ecogentrification, and the Uneven Valorization of Social Reproduction", Annals of the American Association of Geographers, 108:2, 579-590 
National Gardening Association. (2014). "Garden to table: A 5-year look at food gardening in America".

Okvat, H. A. and Zautra, A. J. (2011). "Community Gardening: A Parsimonious Path to Individual, Community, and Environmental Resilience”. American Journal of Community Psychology, 47: 374-387.

Osborne, J.L.; Martin, A.P.; Shortall, C.R.; Todd, A.D.; Goulson, D.; Knight, M.E.; Hale, R.J.; Sanderson, R.A. (2007). "Quantifying and comparing bumblebee nest densities in gardens and countryside habitats”. J. Appl. Ecol., 45, 784-792.

Pilgeram, Ryanne. (2012). "Social Sustainability and the White, Nuclear Family: Constructions of Gender, Race, and Class at a Northwest Farmers Market.” Race, Gender, and Class 19(1):37-60.

Quastel, N.(2009). “Quastel Political ecologies of gentrification” Urban Geography, 30 (2009), pp. 694-725

Renner, S. (2016). “Top 10 cities in the U.S. for urban farming.” http://inhabitat.com/top-10cities-in-the-us-for-urban-farming/

Retail, Samuel. Sullivan, Daniel. (2011). “Gentrification and Race: The Case of Alberta Street in Portland, Oregon.” Urban Affairs Review, 47 (3) 413-432.

Rodbell, Philip (1991). “Urban Green and Cold Cash. American Forests” Mar/Apr91, Vol. 97 Issue 3/4, pp. 62-63.

Rodenburg, Caroline, et al (2002). "Urban Economic Indicators for Green Development in Cities”. Greener Management International; Winter 2002 Issue 36, pp. 105-20. 
Saldivar-Tanaka, Laura and Marianne E. Krasny. (2004). "Culturing Community Development, Neighborhood Open Space, and Civic Agriculture: The Case of Latino Community Gardens in New York City.” Agriculture and Human Values 21:399-412.

Sirohi, M.H.; Jackson, J.; Edwards, M.; Ollerton, J. (2015). "Diversity and abundance of solitary and primitively eusocial bees in an urban centre: A case study from Northampton (England).” J. Insect Conserv., 19, 487-500.

Schukoske, Jane E. (2000). “Community Development through Gardening: State and Local Policies Transforming Urban Open Space.” Legislation and Public Policy Vol. 3:351. pp 351-392.

Slocum, Rachel. (2006). “Anti-Racist Practice and the Work of Community Food Organizations.” Antipode 38(2):327-349.

Strauss, A.L., 1987. "Qualitative Analysis for Social Scientists.” Cambridge University Press

Sullivan, W.C., Kuo, F.E., \& DePooter, S.F. (2004). “The fruit of urban nature: Vital neighborhood spaces. Environment \& Behavior", 36(5), pp. 678-700.

Takano, T., Nakamura K., Watanabe M. (2002). “Urban residential environments and senior citizens' longevity in megacity areas: the importance of walkable green spaces.” Journal of Epidemiology and Community Health, 56, pp. 913-918.

The U.S. Department of Housing and Development. (2018). “The 2018 Annual Homeless Assessment Report to Congress."

Voicu, Loan and Been, Vicki. (2008). "The Effect of Community Gardens on Neighboring Property Values.” Real Estate Economics. 2008 Vol. 36 2: pp 241-83 
Wells, N.M., Evans, G.W. (2003). "Nearby nature - A buffer of life stress among rural children. Environment and Behavior", 35, pp. 311-330.

White, M. M. (2011). "D-Town Farm: African American resistance to food insecurity and the transformation of Detroit.” Environmental Practice, 13(4), 406-417.

Wolch, J.R. Wolch, J. Byrne, J. Newell. (2014). “Urban green space, public health, and environmental justice: The challenge of making cities 'just green enough'.” Landscape and Urban Planning, 125, pp. 234-244 